RUSSELL NEUMAN:

\title{
La convergencia no es ciencia-ficción
}

\section{Angélica Heredia E.}

Periodista y profesora de Fundamentos del Peridodismo

en la Escuela de Periodismo de la Universidad Católica

[mheredia@puc.cl]

\section{Cristóbal Marín C.}

Director de estudios del Consejo Nacional de Televisión, Sociólogo y Filósofo por la Universidad Católica de Chile, Master en Ciencias Sociales y doctor (c) por la Universidad de Birmingham, profesor de los magísteres en edición y dirección periodísticas de la Escuela de Periodismo y de Ciencia Política de la Universidad Católica [cristoba@reuna.cl]

En la carrera hacia la convergencia de medios tradicionales, informática y telecomunicaciones, las empresas se esfuerzan por maximizar sus ganancias retrasando la competencia. La apuesta del autor de The Future of the Mass Audience es que ésta es una lucha perdida. La tecnología terminará por imponerse. Y el triunfo de la competencia -sobre toda regulación- en las comunicaciones pondrá a disposición de los ciudadanos un espectro fascinante de alternativas donde elegir, «un patio de diversiones intelectual", donde el modelo es internet. Éstas son algunas de las predicciones que expuso el experto norteamericano en su primera visita a Chile.

1 fines de los 80, Russell Neuman llevó - a cabo una decisiva investigación sobre la influencia de las nuevas tecnologías comunicacionales en la vida pública. Su objetivo era examinar la tesis, sugerida por muchos analistas, de que las nuevas tecnologías llevarían a una fragmentación de la audiencia masiva con la consecuente destrucción del espacio público y la polarización de la vida política. Los resultados del estudio fueron determinantes: por razones vinculadas a la economía de escala de los medios masivos y a los hábitos de consumo medial, el movimiento hacia la 


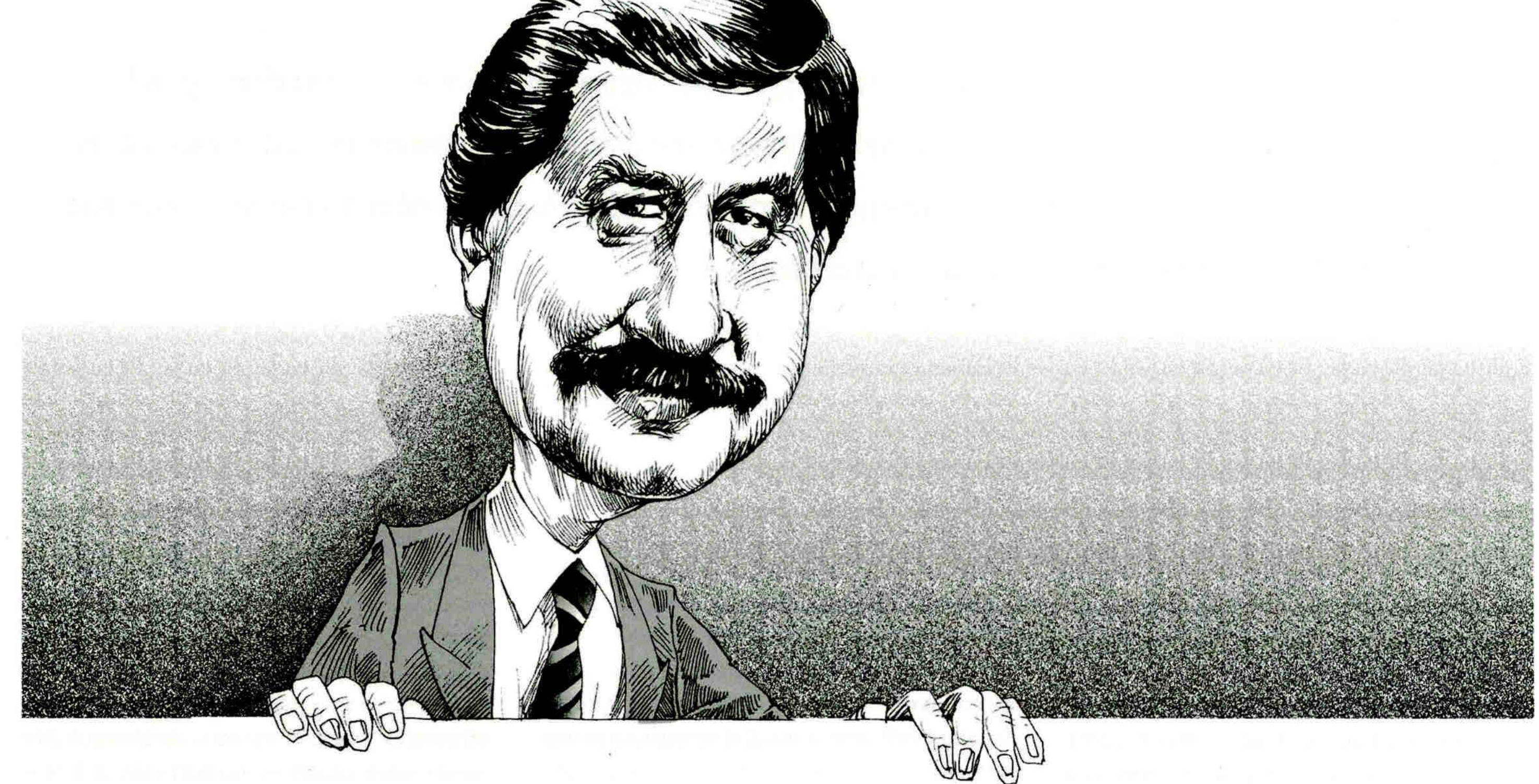

fragmentación sería más bien modesto y la cultura política común no sería mayormente afectada. La investigación, de casi cinco años, fue conducida en el MIT y publicada en 1991 bajo el título The Future of the Mass Audience. Sus planteamientos principales tuvieron un gran poder de predicción.

Neuman vino a Chile como profesor invitado a la versión 1998 del magíster en edición y dirección periodísticas de la $\mathrm{Fa}$ cultad de Comunicaciones de la Universidad Católica. Durante su estadía en el país, dictó además una clase magistral abierta sobre el futuro de las audiencias masivas y participó en un seminario -organizado por la misma facultad y el Centro de Estudios Públicos- sobre las nuevas tendencias en la industria de las telecomunicaciones en Estados Unidos y Europa.

Actor importante en las guerras tecnopolíticas sobre la TV digital, Neuman se reunió en Chile con miembros del Consejo Nacional de Televisión para asesorarlos en la formulación de un marco regulatorio en esta materia. Completó su agenda con otra de las actividades que lo atan al ámbito académico nacional: le tocó comentar el diseño de la investigación para medir, por primera vez, el uso del tiempo de los chilenos en tecnologías de comunicación. En este proyecto, financiado por Fondecyt, trabaja desde marzo de 1998 un equipo de profesores de Periodismo y Sociología de la U.C. Neuman es uno de los integrantes del comité asesor internacional.

Al ocuparse del consumo de tecnologías de comunicación -y no únicamente de medios-la investigación chilena asume un concepto básico para Neuman: la convergencia de medios tradicionales, informática y telecomunicaciones. En el libro The Gordian Knot, que el estudioso norteamericano publicó recientemente junto a sus colegas del MIT, intenta explicar la discusión actual sobre este tema.

— ¿Está siendo efectiva la convergencia entre las industrias de las telecomunicaciones, la informática y los medios masivos y de contenidos?

- Creo que existe la posibilidad técnica de que medios y tecnologías de comunicación independientes converjan en un único gran medio de comunicación digital. La pregunta es si esto será una realidad y si ocurrirá pronto. En mi análisis, especialmente en The Future... he hablado de dos fuerzas en conflicto: la sicología de la audiencia y el aspecto económico de los medios. Sin embargo, en The Gordian Knot, no dibujé dos héroes peleándose. Podría haberlo hecho. Si así fuera, la ganadora sería la tecnología. El interés [de la industria] en el capitalismo es proteger su mercado y evitar la competencia para obtener mayores ganancias. En este esce- 


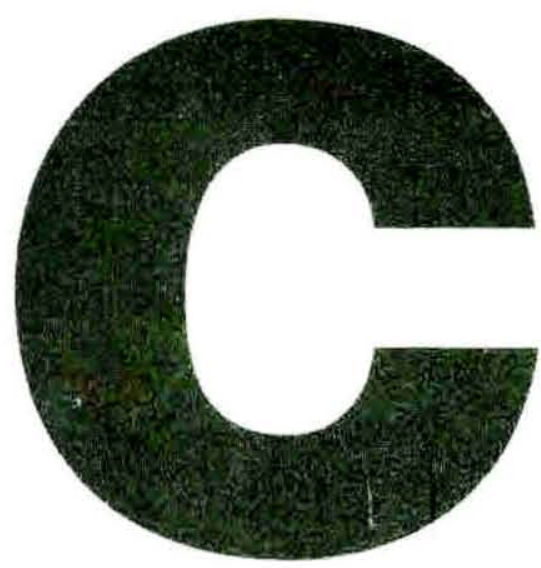

\section{reo que las personas que le temen a la diversidad y al conflicto que podría traer internet no tienen suficiente fe en nuestros colegas y niños. Ellos estarán felices con las miles de posibilidades.}

nario, la industria de las comunicaciones se pregunta, ¿qué puedo hacer para reducir la competencia y, a la vez, desacelerar la integración digital? La tecnología contesta confiadamente: "La integración es fácil de hacer".

"Existe este maravilloso dilema: nadie quiere ser el primero que realice la integración sino que todos quieren esperar hasta que sea inevitable. Creo que una vez que ocurra y sea un fenómeno exitoso, todos querrán sumarse al mismo tiempo. Pienso que sucederá un proceso similar a lo que ahora está ocurriendo en periódicos como The New York Times, que en un momento dijeron "no sé si es bueno o importante para mí estar en internet" y ahora es claro que no se puede estar afuera. Así, la convergencia es el resultado de la presión de la tecnología en el ejecutivo y el regulador. Creo que la historia de la televisión de alta definición en EE.UU. es similar. En su momento, las cadenas de TV bajaron el ritmo y dijeron "no sé, pensémoslon, pero luego la tecnología siguió su curso permitiendo producir televisión de alta definición. Este año se realizan las primeras transmisiones."

- ¿Cuáles podrían ser las consecuencias económicas de reunir tres o cuatro industrias distintas?

- Cada industria estaba feliz y acostumbrada a una situación de casi monopolio en la entrega del servicios de teléfonos, televisión o de periódico. A cada una le hubiera gustado tener su nicho y protegerlo de la competencia. Por otra parte, el objetivo del consumidor, del académico y del regulador es protegerse contra los instintos de estas empresas, que suelen apuntar hacia la idea: "Bueno, déjenme tener mi pequeño nicho proteccionista". [Las empresas] piensan: "quiero que usted le ponga impuestos a los demás y que proteja mi audiencia. Si usted quiere que sirva para fines educacionales o que le ponga teléfonos a los pobres, proteja mis ganancias".

"Mi argumento es que, en vez de proteger las ganancias, permitamos que un menor precio, por ejemplo del servicio telefónico, sea producto de la competencia y no de la regulación. Mi predicción es que las actuales empresas de cada sector de las comunicaciones encontrarán formas más creativas y sofisticadas para retrasar la competencia. Puede ser muy interesante la batalla de la tecnología, los especialistas y los reguladores tratando de generar competencia real entre estas industrias. Lo harán y creo que ganarán."

\section{LA CONVERGENCIA COTIDIANA}

- ¿Y cuáles serán las consecuencias para los hábitos de consumo de medios en el hogar?

-Actualmente un hogar promedio puede tener siete canales de televisión, cinco periódicos, unas veinte radios; pero parece que aún podría haber cierto grado de elección mayor. Existe la duda sobre qué sucedería si en internet hubiera miles de radios, diez mil canales de televisión, TV satelital y cientos de cosas más. Muchos creen que serán demasiadas alternativas. Mi investigación señala que la gente se fascina con la posibilidad de elegir.

"A los que dicen que hay una sobrecarga de información y un problema de elecciones, les diría que imaginen a un niño pequeño que entra a una maravillosa biblioteca y que ve cientos de libros sobre temas interesantes como naturaleza, historia, ciencia. Si ve que cada escalera lo lleva a libros interesantes, ¿se asustaría o lo tomaría como un patio de diversiones intelectual donde puede subir corriendo escaleras, sacar libros, leer unas cuantas páginas, dejarlos nuevamente en su lugar, abrir los estantes y encontrar más libros? Creo que las personas que le temen a la diversidad y al conflicto que podría traer internet no tienen suficiente fe en nuestros colegas y niños. Ellos estarán felices con las miles de posibilidades."

-En The Gordian Knot usted reflexiona sobre cómo las distintas tecnologías de comunicación se han adaptado a los hábitos del hogar y han encontrado su espacio de manera de no suplantarse entre sí. ¿Qué pasará con la llegada de internet?

- ¿Puedo contar una historia? Gracias a nuevos desarrollos en la tecnología de impresión, el diario logró masificarse, reducir mucho los costos y, por lo tanto, 
llegar a personas muy pobres en Europa, Asia y Latinoamérica. Más tarde apareció la radio que se podía escuchar en la noche. Los diarios pensaron que la gente dejaría de leerlos y se preocuparon mucho. Sin embargo, lo que en realidad ocurrió fue que la radio y los diarios se hicieron amigos e incluso se vendían más diarios a raíz de programas como las comedias, los concursos o los dramas en la noche. La gente compraba el diario no sólo para leer las noticias, sino también para averiguar qué habría en la radio esa noche.

"Luego, apareció la televisión y la radio se preguntó si ésta la reemplazaría. La TV hizo cambiar a la radio, que empezó a ser utilizada en la cocina y en el auto. El televisor se acomodó en el living, luego en el dormitorio y ahora, en vez de sentarnos a mirar una radio, la escuchamos mientras hacemos otras cosas, incluso ver televisión.

"De este modo, cuando aparecieron estos medios encontraron su espacio cambiando los hábitos mediales, pero no suplantándose unos con otros. Cada medio por estar diseñado para satisfacer necesidades específicas ya sea sicológicas, económicas o sociales- cumple un rol distinto."

- ¿Sucederá lo mismo con internet?

-No. Internet es la excepción, debido a que puede ser una radio, un televisor y un diario. Los combina a todos y -al igual que un camaleón- puede adoptar la forma que quiera. Tiene propiedades que optimizarían ciertos tipos de usos y hábitos mediales. Si bien internet no es el único nuevo medio de comunicación, sí es el más importante. Es el modelo de convergencia digital en un medio único. Lo maravilloso de un medio único es que resume a todos los otros, agregando además cosas nuevas.

- ¿Cuando escribió The Future... todavía no se desarrollaba internet. ¿Cree que en el actual escenario las tesis de su libro todavía son correctas?

-Estoy muy orgulloso de los argumentos fundamentales de ese libro. Algunos lectores me dicen: "usted no nos anticipó internet", lo cual en parte es verdad. Pero yo les respondo que la exposición sobre las propiedades genéricas de los nuevos medios en The Future... está reflejada muy fuertemente en internet. Así que en cierto modo, el libro predijo y anticipó la evolución de internet. Tal vez algunos argumentos podrían ser modificados, pero la dinámica fundamental entre economía, tecnología y sicología de la audiencia presionándose unas a otras es la misma dinámica que influirá en la evolución de internet, tal como ocurrió en la televisión abierta y de cable.

- ¿Qué opina del proceso de fragmentación de audiencias que está afectando principalmente a las tres grandes cadenas de televisión norteamericanas?

-Cuando empecé la investigación para The Future..., a principios de los 80 , la audiencia televisiva había bajado de 90 a $80 \%$ en los tres principales canales en EE.UU.: $A B C, C B S$ y $N B C$. Las preguntas eran: ¿Qué tan lejos iremos? ¿Qué pasará si la audiencia llega a un 10\%? ¿Se destruirá con esto la TV comercial? Lo que sucedió fue que la audiencia llegó a $60 \%$ y ha estado fluctuando entre 60 y $50 \%$. Descubrimos que la naturaleza de ese sector del mercado en un país con tantos millones de habitantes es que exista una audiencia popular natural para tres o cuatro canales. Ahora la Fox se les ha unido y tenemos que más o menos la mitad de las personas ve los cuatro canales. Existen otros cien canales, incluyendo History Channel, Discovery Channel y CNN, y todos tienen audiencias muy pequeñas, pero sus niveles de costos también son muy pequeños. Se llegó a esta mezcla interesante de medios masivos grandes y medios masivos medianos. Así, creo que redescubriremos en la tecnología audiovisual el equivalente a una pequeña revista con éxito desde el punto de vista comercial y una circulación de sólo 10.000 ejemplares. Me parece que estos desarrollos son posibles y deberían ser protegidos.

- ¿Cuál cree entonces que es el futuro de la audiencia masiva?

- La definición de una audiencia masiva cambia de un medio a otro. Una grabación, un $\mathrm{CD}$, un libro o un programa de televisión, cada uno tiene sus propias medidas. $\mathrm{Al}$ inicio de The Future... se dice que en un grupo -que puede ser una fiesta, una comida, cualquier reunión en que hay más de doce personas en una mesa- se dificulta la posibilidad de comunicarse unos con otros. Sabemos que para que un programa tenga éxito, tiene que tener algún porcentaje de audiencia. Pero también sabemos que existe un área o grupo de tamaño intermedio que usa los medios electrónicos.

"Sabemos que no existe un programa de televisión que tenga éxito con una audiencia de cien televidentes. Eso no existe, no es la esencia de este medio. Por supuesto que hay modos de comunicación -como una conversación telefónica o una carta- que se dan entre dos personas, y. eso sí tiene sentido. En un lado está la llamada telefónica, que sólo necesita de dos personas y en el otro, la televisión y su enorme masividad. Lo que internet y el nuevo medio crearán es una nueva forma intermedia con una audiencia también intermedia en cuanto a tamaño.

"Actualmente, lo que más se asemeja a esto en EE.UU. serían las llamadas newsletters donde dos o tres personas se juntan una vez al mes y tipean tres o más páginas. Las ordenan, las imprimen y las envían por correo. Es posible que tengan entre cien y 
mil suscriptores, no importa. Pueden ser de un club local, sobre un tema que les interesa: perros, observadores de pájaros, ajedrez o política local. Antiguamente, antes de que la imprenta generara un medio masivo en los años 1830-1840, existía una tradición de escribir panfletos, como los escritos por Thomas Paine. Creo que el regreso de los panfletos es un adelanto atractivo, aunque en verdad no es tan nuevo.

"La industria televisiva es un negocio que busca ganar dinero al vender noticias profesionales y entretención. La persona que llama por teléfono está en el negocio de hablar con un amigo y es algo expresivo. El propósito de esa llamada es lograr la comunicación entre dos personas. En la persona que escribe panfletos se da una mezcla. No lo hace por dinero sino porque quiere expresar sus ideas. Esto es un nuevo adelanto maravilloso y puede ser un retorno a lo mejor del espíritu público del siglo XIX."

\section{NOVIEMBRE 1998: NACE LA TV DIGITAL}

-Usted ha sido un actor importante en los debates sobre TV digital. ¿Qué opina del modelo que se está implantando actualmente en EE.UU?

-El modelo norteamericano es interesante. A cada canal de televisión analógi$\mathrm{co}$, se le dio de modo gratuito otro canal para que trasmitiera simultáneamente en forma analógica y digital. Hasta donde sé, en Chile ha habido fuertes argumentos para seguir este modelo. El punto es que la transmisión digital y el aparato de televisión digital serán caros, por lo que su difusión será más lenta que el paso de la televisión en blanco y negro a la en colores.

"No estoy seguro de si el norteamericano es un buen modelo-ya sea para EE.UU.

\section{QUÉ HA HECHO, QUÉ HA ESCRITO}

Russell Neuman es doctor en sociología por la Universidad de California, Berkeley. Profesor de comunicaciones y director del programa Information and Society del Annenberg Center for Public Policy, Annenberg School for Communication, Universidad de Pennsylvannia. Ha sido consultor para el congreso de EE.UU., el parlamento ruso (Duma) y numerosas industrias comunicacionales tales como AT\&T, The New York Times, Washington Post, CBS, ABC, NBC, Time Warner, Xerox y Telebras de Brasil.

\section{ACTIVIDAdES ACADÉmICAS}

1997-PRESente Profesor de comunicaciones y director del programa Information and Society del Annenberg Center for Public Policy, Arınenberg School for Communication, Universidad de Pennsylvannia.

1996-1997 Profesor visitante de Política y políticas públicas en el Joan Shorenstein Center on the Press, Politics and Public Policy, Kennedy School, Harvard University.

1992-1997 Profesor de Comunicación Internacional, Fletcher School, Universidad de Tufts

1985-1992 Profesor e investigador asociado en el Massachusetts Institute of Technology (MIT), Departamento de Ciencia Política y Laboratorio de Medios.

1984-1 985 Investigador visitante, Universidad de Harvard, Programa Information Resources Policy.

1980-1985 Profesor e investigador en el Massachusetts Institute of Technology, Departamento de Ciencia Política y Programa de investigación en Políticas de Comunicación.

1975-1980 Profesor asistente, Universidad de Yale, Departamento de Sociología.

1972-1975 Investigador, Universidad de California, Berkeley, Proyecto Mass Communications.

\section{Publicaciones (SELEcción)}

En Prensa (con MARCus, GeOrge y MACKUEN, MiCHAEL): Affective Intelligence and Political Judgment, University of Chicago Press.

EN PRENSA "The Global Impact of New Technologies» en GRABER, DORIS; MCQUAIL, DENIS; NORRIS, PIPPA (eds.): The Politics of News: The News of Politics.

1997 (con MCKNIGHT, LEE W. y SOLOMON, RICHARD J.): The Gordian Knot: Political Gridlock on the Information Highway, MIT Press.

1995 (con MCKNIGHT, LEE W.) "Technology Policy and the National Information Infrastructure," en DRAKE, WILLIAM J. (ed.): The New Information Infrastructure: Strategies for U.S. Policy, Twentieth Century Fund Press, New York.

1995 «Is the Public Ready for News on Computers?» en Nieman Reports, otoño.

1994 (con MCKNIGHT, LEE W.; FERRO, JOSÉ ROBERTO y BOTELHO, ANTONIO JOSÉ J.): “Brazilian Telecommunications in Transition: A New Strategy for Competitiveness", Telebras, Brasilia, septiembre.

1992 (con JUST, MARION Y CRIGLER, ANN): Common Knowledge: News and the Construction of Political Meaning, University of Chicago Press.

1992 (con SAPOLSKy, HARVEY; NOAM, ElI y CRANE, RHONDA (eds.)): The Telecommunications Revolution: Past, Present and Future, Routledge.

1991 The Future of the Mass Audience, Cambridge University Press.

1986 The Paradox of Mass Politics: Knowledge and Opinion in the American Electorate, Harvard University Press.

1986 (con POOL, ITHIEL DE SOLA), "The Flow of Information Into the Home», en BALL-ROKEACH, SANDRA y CANTOR, Muriel (eds.): Media, Audience and Social Structure, Sage Publications, Beverly Hills.

1982 «Television and American Culture», en Public Opinion Quarterly, vol. 46, ํㅜ 4, invierno.

1976 " «Patterns of Recall Among Television News Viewers», en Public Opinion Quarterly, vol. 40, n¹, primavera. 
o para otros lugares-, porque tiende a disminuir el uso del espectro actual, en lugar de mejorarlo para estimular la competencia y experimentos nuevos. Es bastante inútil que se transmita al mismo tiempo en forma separada. Cada nueva tecnología puede ser formulada de manera tal que limite o aumente la competencia. Creo que las fuerzas conservadoras de las actuales cadenas de TV en EE.UU. usan su gran poder y sofisticación política para lograr un acuerdo que las beneficie a ellos y no necesariamente al público. Me parece que con una pequeña modificación la televisión digital podría ser diseñada de manera de que ocupe menos espacio radioeléctrico y utilice el espectro en forma más eficiente."

- ¿Cuáles cree que podrían ser los cambios más importantes en la TV norteamericana con el comienzo de las trasmisiones digitales, programadas para noviembre de 1998?

- Gracias a la digitalización, técnicamente hoy en día podemos concentrar mucha información en espacios muy pequeños. Por ejemplo, en el espacio radioeléctrico que ocupa un canal analógico se pueden transmitir de cinco a diez canales digitales o uno digital de alta definición. Por lo tanto, al pasar de la TV analógica a la digital se tendrá que decidir si esa capacidad se utilizará para generar diversidad o sólo para mejorar la resolución de la imagen. Esta decisión aún no se resuel- ve en EE.UU. Espero que la transición hacia la TV digital abra una discusión social sobre la forma de utilizar esta tecnología para entregar mejor resolución, competencia y también diversidad.

-Usted ha trabajado en algunas investigaciones sobre el futuro de las noticias. ¿Cuáles son sus preocupaciones en este campo?

-Creo que la esencia del papel del periodista, más que informar al lector interesado, es captar la atención de un lector medianamente interesado. Así, el periodista que inventa un titular, que llama la atención con una frase, una imagen o una buena fotografía hace buen periodismo. La diversidad del periodismo cambiará incluso más en internet, donde hay movimiento, sonido e imágenes, integrados en forma novedosa y entretenida.

"Entregar buenas explicaciones y contexto a los hechos noticiosos también será cada vez más importante. A la gente le gustaría que el ciudadano promedio pusiera atención a asuntos sobre filosofía, arte, política, elecciones en países lejanos, los conflictos en Europa o Asia. Sin embargo, la naturaleza de las personas hace que haya una tensión saludable entre el ideal del ciudadano educado y la realidad práctica de la persona cuyos hijos se enferman, y que no tiene tiempo para leer extensos artículos sobre la crisis asiática. Creo que el debate sobre esta tensión aumentará.

"Los editores y los periodistas de dia- rios importantes como The New York Times, ElMercurio, y The Times, imponen lo que debería estar en el diario. Si analizamos los diarios veremos que hay una parte importante de noticias internacionales y reseñas de libros sobre filosofía o arte que los lectores no leen. En la televisión, sabes lo que dice el rating; en los periódicos, puedes saber su circulación, pero si en el diario hay un artículo muy aburrido sobre la crisis asiática que nadie lee, nunca lo sabrás. Porque estaba en la primera página, se piensa que es importante. La gente lee lo que quiere leer en los diarios.

"En el mundo de la televisión y en el mundo digital será más evidente que nunca que la condición humana no alcanza este ideal del ciudadano educado. Esto fue así en 1850 , en 1950 y también lo será en el 2000 , sólo que ahora tenemos evidencia electrónica de que es verdad. Creo que podemos seguir manejando esa tensión saludable entre el ideal y la realidad. Me parece apropiado que el periodismo se preocupe de la calidad. No obstante, me parece que lo que el ciudadano promedio aprende a través de los medios cambia muy poco mientras que los medios cambian en gran manera. Esto es una paradoja."

- La revolución en las comunicaciones supone un desafío importante para la investigación en esta área. ¿Cuáles cree que son las nuevas tendencias principales en la investigación sobre la comunicación?

-Para nosotros, los investigadores

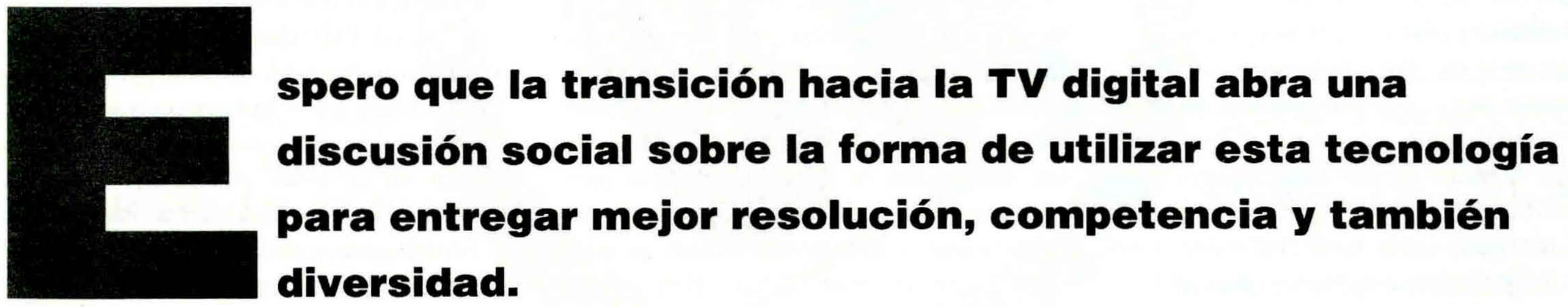

